\title{
National Presentation of India
}

\author{
K. Subramaniam
}

\section{The National Presentation Process}

A proposal to make a national presentation on the status of mathematics education in India at ICME-12 was sent by the Indian National Science Academy to the Chairman of the International Programme Committee in February, 2011. After the proposal was accepted, a Steering Committee was formed to oversee the preparation of the National presentation. A national initiative was launched to identify initiatives and innovations in mathematics education in India and to bring diverse groups working to improve mathematics education together on a common platform. The National Initiative on Mathematics Education (NIME) aimed to develop a vision about the changes necessary in mathematics education policy, the need for research studies on mathematics education, and ways of implementing system wide improvement and transformation of the practice of mathematics education.

Under the NIME initiative five regional conferences on mathematics education were held in 2011 across India to provide a wide participatory platform. This was followed by a National Conference on mathematics education in early 2012. The aim of the conferences was to bring together the important and significant innovations and efforts to improve mathematics education in school and in higher education in the diverse regions of the country and to build awareness of such efforts in the community of mathematics educators. The proceedings of the conferences formed an input for the Indian National Presentation.

The Indian National Presentation at ICME-12 includes the following components:

1. A book on Mathematics Education in India: Status and Outlook, containing key articles on the themes identified for the National Presentation.

K. Subramaniam $(\square)$

Homi Bhabha Centre for Science Education, Mumbai, India

(C) The Author(s) 2015

S.J. Cho (ed.), The Proceedings of the 12th International Congress

on Mathematical Education, DOI 10.1007/978-3-319-12688-3_23 
2. The slides of the presentations made at ICME-12 in two slots: one sub-plenary slot of $90 \mathrm{~min}$, and a parallel session of $90 \mathrm{~min}$.

3. Four video films ( 1 long and 3 short) on the challenges and hope giving initiatives in mathematics education in India.

4. An exhibition covering historical aspects of mathematics and mathematics education, the challenge of diversity, basic data about mathematics education in India and information about some initiatives displayed in a stall in the exhibition area of ICME-12.

All these components, except the long video film, are available on the NIME website for free download under an open access license: http://nime.hbcse.tifr.res.in. The website also contains links to the NIME regional and national conference websites, and the research papers presented by Indian participants at ICME-12.

\section{Mathematics Education in India}

The Indian National presentation was organized under the following four major themes:

1. Historical and Cultural aspects of mathematics and mathematics education

2. Systemic and Policy aspects of education

3. Mathematics Curriculum and Pedagogy at the elementary, secondary and tertiary levels (including nurture and enrichment programmes)

4. Teacher education and development

We provide below a summary of the presentations made for the Indian National Presentation (presentation slides available on the NIME website). The book on Mathematics Education in India: Status and Outlook, may be consulted for more details. The first presentation session covered the first two themes, while the remaining themes were covered in the second presentation session.

\section{Historical and Cultural Aspects of Mathematics and Mathematics Education}

There were two presentations under this theme, the first on the history of Indian mathematics and the second on the history of Indian mathematics education. Ramasubramaniam presented an overview of the historical tradition of mathematics in India. He described the main contributions made by Indian mathematicians in the Ancient Period (prior to 500 CE), the Classical Age (500-1200 CE) and the Medieval Period (1250-1750 CE). The examples that he described included the knowledge of geometry used to identify the cardinal directions and methods of finding irrational quantities such as square roots in the Sulbasūtras ( 500 BCE), 
Aryabhata's recurrence relation for sine values as well as the table of sine differences (499 CE), the summation of series and finding the sums of sums in the Classical Age, and the infinite series for $\pi$ and the fast converging approximations developed in the Kerala school of mathematics in the Medieval Period. He pointed out that the Indian approach to mathematics laid emphasis on the development of algorithms and on practical applications. Indian mathematical texts typically illustrated a principle or rule with a large number of examples drawn from the practical world. He also pointed out the role of memory in communicating mathematics and the organization of the texts in compressed verse form (sütras). He argued that inclusion of the history of mathematics in mathematics education would help eliminate euro-centrism and biases, and also introduce a cross-cultural perspective on mathematics.

Senthil Babu spoke about the indigenous traditions of mathematics education in pre-British South India. Indian merchants, traders and craftsmen were renowned for their facility in arithmetic and computational ability. They learned to carry out a variety of complex computations grounded in practical contexts in indigenous schools called "pāthaśälas". The curriculum in these schools was grounded in the needs of the economy and society. The objective of the päthaśäla education was to produce competence and skill in dealing with numbers and letters. A primary mode of learning was recollective memory, which combined knowledge of tables and series of numbers and quantities with problem solving. Public display of competence and skill was a celebrated part of pạthaśāla learning. The encounter with the Colonial British government and the efforts to introduce modern education gradually led to the pāthaśălas being appropriated and replaced with a curriculum and education system that was disconnected from the life of the community. Babu pointed to lessons that this may hold for the problems surrounding mathematics education in contemporary India.

\section{Systemic and Policy Aspects of Education}

There were three presentations under this theme covering respectively school education, the assessment culture and nurture programs for high achievers in mathematics. Anita Rampal presented an overview of the challenges and policy initiatives in mathematics education at the school level. Although India is a country with strong mathematical traditions, it is grappling with multiple challenges emerging from endemic poverty and large numbers of children not completing school. The systemic challenges include restructuring the education system to ensure an equitable education of high quality to a huge young population with high aspirations. Rampal presented an overview of the institutional structures and organization of mathematics education at various levels in India. She described two major policy initiatives in school education - the National Curriculum Framework of 2005 and the Right to Education Act of 2009. The new curriculum framework, which emphasized learning through activity and exploration and making the child 
free from fear and anxiety, had major implications for mathematics education. The new Act has set in place assessment reforms that can have a major impact. The new textbooks at the primary level aim to build on how children think and integrate themes from work, crafts and cultural hertiage. Rampal argued for redesigning secondary education curricula to meet the needs of a diversity of learners and called for a culturally responsive critical pedagogy of mathematics education.

Shailesh Shirali spoke on the role of assessment in mathematics education in India. He described the high stakes, highly competitive examination environment that students in India face at the end of schooling in order to gain entry to higher education. Such intense competition has led to a pervasive culture of private coaching and has shaped assessment practices right down to the primary school level. Shirali discussed sample questions from some of the most competitive entrance examinations, which tend to emphasize procedure and manipulative skills, and heavy dependence on memorization. He described the recent initiative on "continuous and comprehensive evaluation" as promising, but as critically dependent on adequate teacher preparation. He also called for research on assessment tools and models.

Kumaresan described the training programs at different levels aimed at high achievers in mathematics in India. He grouped the training programs under three categories: (i) those at the undergraduate level (ii) those at the graduate and Phd level and (iii) those aimed at National Olympiad toppers. The most significant program at the undergraduate level is the Mathematics Training and Talent Search (MTTS) program. This program aims to move students out of a pervasive culture of rote learning towards discovering mathematics by inquiry, to awaken their thinking abilities, to expose them to the excitement of doing mathematics, and to change the teaching of mathematics in the country in the long run. The MTTS sessions are highly interactive, where students are trained to observe patterns, formulate conjectures and develop proofs. The Advanced Training in Mathematics (ATM) schools address the needs of graduate and Phd level students. Olympiad toppers are trained through a special nurture program.

\section{Mathematics Curriculum and Pedagogy at the Elementary, Secondary and Tertiary Levels}

There were four presentations on the mathematics curriculum and pedagogy at different levels of education in India. The first two presentations described the curriculum and the pedagogical challenges at the primary level. The remaining two presentations analysed the curriculum at the secondary and tertiary levels of education. Amitabha Mukherjee described the changes introduced in the primary mathematics curriculum and textbooks following the revision of the school curriculum framework by contrasting the new curriculum and the traditional curriculum along several dimensions. The new curriculum emphasises concrete experience 
as the basis for learning mathematics, and encourages multiple approaches to solving problems. Topics not emphasised in traditional curriculum such as shapes and space, measurement, data handling and patterns have been given space in the new curriculum. Jayasree Subramanian analysed the limitations of well-intentioned reforms in primary mathematics education. She pointed out that activity based approaches need resources in the form of teaching-learning materials, which are not available in most schools catering to children from low socio-economic backgrounds. "Drill and practice" still dominates classroom teaching of mathematics. Jayasree Subramanian cautioned that curriculum and pedagogy alone cannot ensure mathematics for all in a society fractured by several inequities.

Jonaki Ghosh presented an overview of the secondary mathematics curriculum, where the central focus is on consolidation of concepts learned earlier and exploring wider connections. There is an emphasis on the structure of mathematics as a subject and mathematical processes such as argumentation and proof, logical formulation, visualization, mathematical communication and making connections. While assessment is largely summative, a new initiative by the Central Government has shifted the emphasis towards continuous and formative assessment by removing the mandatory requirement of a final public examination at the end of Grade 10 . The senior secondary stage (Grades 11-12) is dominated by the culture of highstakes examinations, and Ghosh identified areas where a change of approach is needed, especially of making students familiar with the power of applications of mathematics in solving real world problems. She also emphasised the role of technology and the need to apply it thoughtfully to overcome the challenge of resource-poor classrooms.

Geetha Venkataraman spoke on the challenges facing mathematics education at the tertiary level where there are about 400 Universities and 18,000 colleges offering undergraduate courses in mathematics. Although syllabus reforms have taken place in the undergraduate curriculum since the late 1960s and 1970s, further reform is needed at the present time. The recommendations and model syllabus of the University Grants Commission failed to provide leadership in terms of applicability of mathematics and the use of information technology in mathematics education. The pedagogy followed is largely one of demonstrating content by stating and proving theorems with minimal student interaction. Assessment typically requires students to reproduce from memory rather than to think, analyse and solve problems. There are almost no pre-service training or inservice training programs available for faculty to learn about teaching methods and tools. Geetha Venkataraman also called for better links between the community of research mathematicians and mathematics educators.

\section{Teacher Education and Development}

There were two presentations on teacher education and development, one focused on the organization of pre and in-service teacher eduation and one on innovations 
and initiatives in teacher education. Ruchi Kumar presented an overview of the structures and institutions implementing teacher education in India and the place of mathematics education in the teacher education curriculum. The new school curriculum framework demands a revisiting of teachers' beliefs, a strengthening of content knowledge of mathematics and a better understanding of the psychology of young children. Ruchi Kumar gave some examples of what aspects of teacher education need change. She concluded that research on teachers' beliefs and knowledge and the relation of these to student learning was greatly needed but largely absent in the Indian context. Subramaniam spoke about the trends of change in mathematics teacher education in India and the sources of change. He cited the example of the innovative program for preparing primary mathematics teachers launched in the 1990s by the Indira Gandhi National Open University. The curriculum of this program aimed at addressing teachers' beliefs about mathematics and its learning and at giving them experiences of exploring interesting mathematics. He also mentioned some in-service teacher development initiatives as harbingers of change in mathematics teacher education. He emphasized the role of teacher associations in bringing about change in mathematics teaching at the secondary level and called for greater participation by the associations in framing curricula for pre-service teacher education.

The final presentation by Rakhi Banerjee presented a brief review of research in mathematics education in India, which is still a highly under-developed research domain in the country. Traditional studies typically follow psychometric models aiming to identify learning difficulties in mathematics or factors responsible for poor achievement in mathematics. She described some promising new trends in mathematics education research in the country which include intervention studies aimed at alternative learning trajectories for key concepts such as whole numbers, fractions or algebra. Research studies on teacher education and development are very much needed, but are nearly absent. She criticised traditional studies for failing to provide insights into the nature of the problem or possible solutions. The new research studies often lack methodological rigour or a strong theoretical framework. She also pointed to the lack of adequate support in the universities for mathematics education research and the isolation of education departments from subject disciplines as factors hindering the growth of mathematics education research in the country.

Three short video films, screened at the end of the first presentation session, had the following titles: (i) Legacy of maths at work and play (ii) Diverse learners multiple terrains (iii) Initiatives to transform maths learning. These video films and the presentation slides can be found at http://nime.hbcse.tifr.res.in.

Open Access This chapter is distributed under the terms of the Creative Commons Attribution Noncommercial License, which permits any noncommercial use, distribution, and reproduction in any medium, provided the original author(s) and source are credited. 